\title{
Study on Inner Mongolia City Economic Relations from the Perspective of Social Network Analysis
}

\author{
Liu Yajing ${ }^{1, a, ~ * ~}$ \\ ${ }^{1}$ Hebei Jiaotong Vocational and Technical College, No. 219 Zhujiang Road, Shijiazhuang, China \\ a1129909869@qq.com \\ ${ }^{*}$ Liu Yajing
}

Keywords: Inner Mongolia; city economic contacts; modified gravity model social network analysis

\begin{abstract}
The coordinated development of city in Inner Mongolia is of great significance to maintain the stability of northern frontier of China and foreign trade. The paper, based on the modified gravity model, applying social network analysis method and Ucinet analysis software to contract the city economic contacts network of Inner Mongolia autonomous region, and make a solid evidence analysis of the $12 \mathrm{EU}$ economic contacts and network characteristics. Through the analysis, it can be found that the economic contacts have become more and more closely among the EU and Inner Mongolia, but the overall situation is not high, city development is not balanced, the city level show a ladder condition, the economic ties is mainly concentrated in the "HuBao-E" economic circle, and the economic circle has played significant role in promoting the development of Inner Mongolia Autonomous Region. Finally, according to the above analysis, some suggestions were put forward to optimize the city economic contacts in Inner Mongolia. Study on the network structure of Inner Mongolia city economic contacts is a basis for drawing up the development strategies of city and region.
\end{abstract}

\section{Introduction}

In recent years, Inner Mongolia's economy has developed rapidly, but due to the influence of geographical location, historical culture, resource environment and institutional policies, the development of various alliances is relatively unbalanced. Inner Mongolia is located in the northern frontier of China, bordering Inner Mongolia and Russia in the northwest. It has a vast territory, rich mineral resources, tourism resources, agricultural resources and animal husbandry resources. It has a profound cultural heritage and spans the northeast, north and northwest regions. It is a coordinated development radiation zone in Jing-jin-ji Regional, shouldering bilateral trade with Russia, Mongolia and Eastern European countries. Strengthening the study of the economic ties between Inner Mongolia cities is not only conducive to determining the economic status and role of the various cities in regional development, but also can play their respective advantages according to the characteristics of ethnic regions, reciprocal development, and realize the rational utilization of the urban resources and geographical advantages, so as to provides a basis for formulating urban and regional development strategies. 


\section{Research method and data sources}

Gravity model analysis is a method for calculating spatial economic linkage values, and is the source and basis of relational data for SNA analysis.

$$
R_{i j}=k_{i j} \frac{\sqrt{P_{i} \times G_{i}} \times \sqrt{P_{j} \times G_{j}}}{D_{i j}^{2}}, k_{i j}=\frac{G_{i}}{G_{i}+G_{j}}
$$

In the form: Rij is the economic connection of city i to city $\mathrm{j} ; \mathrm{Pi}$ and $\mathrm{Pj}$ are the urban non-agricultural population of urban i and city j respectively; Gi and Gj are the urban GDP of city $i$ and city j respectively; Dij is the distance between city $\mathrm{i}$ and city j; Kij is the contribution rate of city i to Rij.

Social network analysis is a method to study social actors, social relations and network structure. He takes "relationship" as the research object, takes the relationship model of the research object as the structure, and analyzes the influence of this structure on its members or the whole ${ }^{[1]}$.In this paper, network density, network centricity, cohesive subgroups, core-edge structure analysis and other indicators are selected to calculate and analyze the economic links of 12 cities in Inner Mongolia.

Taking into account the development trend of the economic linkage network of Inner Mongolia cities, the availability and convenience of relevant data, this paper selects the relevant economic data of five time points that are 2008,2010,2012,2014 and 2016, with a time span of 8 years, and a uniform distribution of time points can reflect the changes in the economic network structure of Inner Mongolia. The traffic data comes from the China Highway Information Network and the Inner Mongolia Expressway map, using the shortest road distance.

\section{The construction of Inner Mongolia's urban economic linkage network}

By using Ucinet-Netdraw drawing software, the intensity matrix of economic links calculated by the modified gravity model is imported into and generated the structural charts of urban economic links of Inner Mongolia in 2008,2010,2012,2014 and 2016.Fig.1 is a comparison chart of urban economic links network structure of Inner Mongolia in 2008,2012,2014 and 2016.Each node in the graph represents the corresponding alliance city, and the directed line segment between nodes represents the economic links between cities and their directions, which can directly reflect the degree of economic ties between cities.

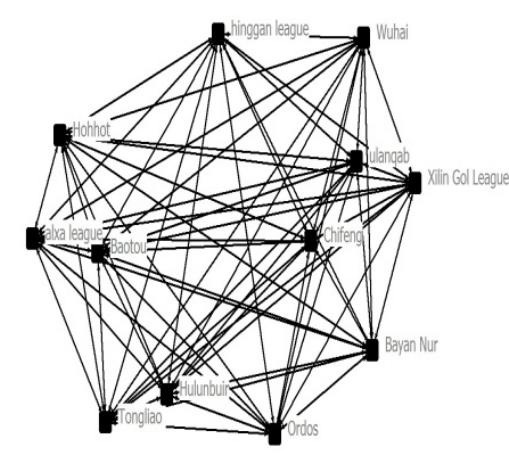

2008 year

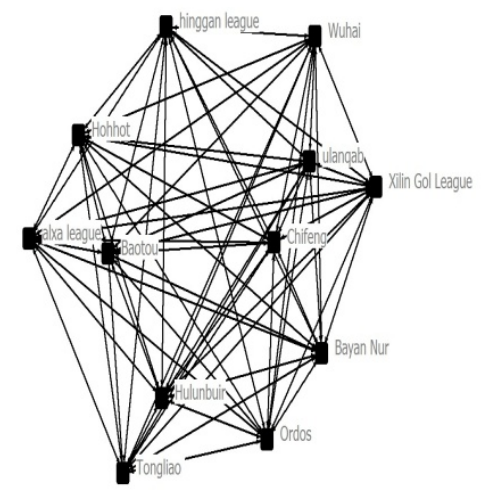

2012 year

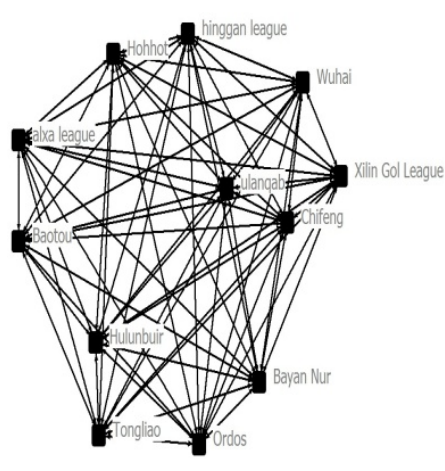

2016 year

Fig.1 Comparison of the economic network structure of Inner Mongolia cities 


\section{Analysis on the Characteristics Change of Urban Economic Contact Network}

\subsection{Network Density Analysis}

Network density refers to the closeness of the relationship between network members. For urban economic networks, the greater the value indicates the closer the economic relationship between cities, the greater the impact of the city's economic network on members, and vice versa. It can be seen from Figure 1 that during the period of 2008-2016, the economic linkage network of Inner Mongolia cities tends to be dense. The central position of Hohhot, Baotou and Erdos is constantly prominent, and the economic links of other alliances are also continuously strengthened. From the quantitative point of view, it needs to be considered from the perspective of network density. Using Ucinet-Cohesion-Density software to calculate the network density of the above five time points is shown in Table 1.

Table 1 Inner Mongolia urban economic connection network density

\begin{tabular}{c|c|c|c|c|c}
\hline Year & 2008 & 2010 & 2012 & 2014 & 2016 \\
\hline Network Density & 0.214 & 0.347 & 0.600 & 0.784 & 1.073 \\
\hline Growth Rates (\%) & - & 61.916 & 73.218 & 30.673 & 36.746 \\
\hline
\end{tabular}

It can be seen from Table 1 that the network density increased from 0.214 to 1.073 in 2008-2016, and the change is more obvious, indicating that the economic ties between cities are getting closer and closer, the degree of interaction is increasing, and the growth rate is first increased and then decreased.

\subsection{Network centrality and Centralization analysis}

Network centrality is a measure of the extent to which a network member is at the center of the network. If a node has the highest degree, the node resides in the network center and has power.

The network center degree results calculated by Network-Centrality-Degree are shown in Table 2 and Table 3.

Table 2 Inner Mongolia city economic connection network centrality-point-out degree

\begin{tabular}{c|c|c|c|c|c|c|c|c|c|c}
\hline Ranking & \multicolumn{9}{|c|}{ Point-out Degree } \\
\hline & \multicolumn{2}{|c|}{2008 year } & \multicolumn{2}{c}{2010 year } & \multicolumn{2}{c}{2012 year } & \multicolumn{2}{c}{2014 year } & \multicolumn{2}{c}{2016 year } \\
\hline 1 & Baotou & 19 & Baotou & 20 & Baotou & $\begin{array}{c}2 \\
1\end{array}$ & Baotou & 19 & Baotou & 17 \\
\hline 2 & Hohhot & 18 & Hohhot & 18 & Hohhot & $\begin{array}{c}1 \\
7\end{array}$ & Hohhot & 15 & Hohhot & 14 \\
\hline 3 & Ordos & 9 & Ordos & 12 & Ordos & $\begin{array}{c}1 \\
3\end{array}$ & Ordos & 14 & Ordos & 13 \\
\hline 4 & ulanqab & 4 & ulanqab & 4 & ulanqab & 4 & ulanqab & 4 & ulanqab & 3 \\
\hline 5 & Chifeng & 3 & Chifeng & 3 & Chifeng & 3 & Chifeng & 3 & Chifeng & 3 \\
\hline 6 & Tongliao & 3 & Tongliao & 3 & Tongliao & 3 & Tongliao & 3 & Tongliao & 3 \\
\hline 7 & Bayan Nur & 3 & Bayan Nur & 3 & Bayan Nur & 2 & Bayan Nur & 3 & Bayan Nur & 2 \\
\hline 8 & Wuhai & 1 & Wuhai & 1 & Wuhai & 1 & Wuhai & 2 & Wuhai & 1 \\
\hline 9 & Hulunbuir & 1 & $\begin{array}{c}\text { Xilin Gol } \\
\text { League }\end{array}$ & 1 & $\begin{array}{c}\text { Xilin Gol } \\
\text { League }\end{array}$ & 1 & $\begin{array}{c}\text { Xilin Gol } \\
\text { League }\end{array}$ & 1 & $\begin{array}{c}\text { Xilin Gol } \\
\text { League }\end{array}$ & 1 \\
\hline 10 & $\begin{array}{c}\text { Xilin Gol } \\
\text { League }\end{array}$ & 1 & Hulunbuir & 1 & Hulunbuir & 1 & Hulunbuir & 1 & Hulunbuir & 1 \\
\hline 11 & hinggan league & 1 & $\begin{array}{c}\text { hinggan } \\
\text { league }\end{array}$ & 1 & $\begin{array}{c}\text { hinggan } \\
\text { league }\end{array}$ & 1 & $\begin{array}{c}\text { hinggan } \\
\text { league }\end{array}$ & 1 & $\begin{array}{c}\text { hinggan } \\
\text { league }\end{array}$ & 1 \\
\hline 12 & alxa league & 0 & alxa league & 0 & alxa league & 0 & alxa league & 0 & alxa league & 0 \\
\hline
\end{tabular}


Point-out degree indicates the degree of active influence of a certain node city on other cities. It can be seen from Table 2 that between 2008 and 2016,the point-out degree of Baotou City and Hohhot City has been ranked higher than other cities, indicating Baotou and Hohhot have been in the core position of Inner Mongolia, but their growth rate is not large, on the contrary, there is a downward trend, which shows that the influence of Baotou and Hohhot on other cities is weakening, and the point output of Ordos city is basically on the rise, indicating that its radiation capacity is increasing, which is in line with the national policy to create the "Hubao-E" economic circle, and the development of regional cities is driven by the radiation of its economic zone. The rankings of Wulanchabu City, Chifeng City, Tongliao City and Bayannaoer City, which are in the middle of the ranking, have basically no change, and they have a relatively important impact on the economic development of Inner Mongolia. They are also not economically connected with other cities in the province. The cities in Wuhai City, Hulunbeier City, Xilin Gol City, Xing'an League and Alxa League have relatively low point and no growth trend. Among them, Wuhai City is a resource-based city with relatively simple economic functions and less close links with other alliances. Due to the geographical location, the cities in the Mengdong area are more closely related to the cities in the three northeastern provinces than the cities in the autonomous region.

Table 3 Inner Mongolia city economic connection network centrality-point-in degree

\begin{tabular}{|c|c|c|c|c|c|c|c|c|c|c|}
\hline \multirow{3}{*}{$\begin{array}{c}\text { Ranking } \\
1\end{array}$} & \multicolumn{10}{|c|}{ Point-in Degree } \\
\hline & \multicolumn{2}{|c|}{2008 year } & \multicolumn{2}{|c|}{2010 year } & \multicolumn{2}{|c|}{2012 year } & \multicolumn{2}{|c|}{2014 year } & \multicolumn{2}{|c|}{2016 year } \\
\hline & Baotou & 13 & Baotou & 15 & Baotou & 15 & Baotou & 14 & Baotou & 14 \\
\hline 2 & ulanqab & 12 & Hohhot & 12 & Hohhot & 12 & ulanqab & 12 & Hohhot & 11 \\
\hline 3 & Hohhot & 11 & ulanqab & 12 & ulanqab & 12 & Hohhot & 11 & Ordos & 10 \\
\hline 4 & Ordos & 11 & Ordos & 11 & Ordos & 11 & Ordos & 10 & ulanqab & 9 \\
\hline 5 & Bayan Nur & 5 & $\begin{array}{c}\text { Bayan } \\
\text { Nur }\end{array}$ & 5 & $\begin{array}{c}\text { Bayan } \\
\text { Nur }\end{array}$ & 5 & $\begin{array}{c}\text { Bayan } \\
\text { Nur }\end{array}$ & 5 & $\begin{array}{c}\text { Bayan } \\
\text { Nur }\end{array}$ & 4 \\
\hline 6 & Chifeng & 3 & Chifeng & 3 & Chifeng & 3 & Hulunbuir & 4 & Chifeng & 3 \\
\hline 7 & $\begin{array}{c}\text { hinggan } \\
\text { league }\end{array}$ & 2 & Wuhai & 3 & Tongliao & 2 & Chifeng & 3 & Tongliao & 2 \\
\hline 8 & $\begin{array}{c}\text { Xilin Gol } \\
\text { League }\end{array}$ & 2 & Tongliao & 2 & Wuhai & 2 & Wuhai & 3 & Wuhai & 2 \\
\hline 9 & Wuhai & 2 & $\begin{array}{c}\text { Xilin Gol } \\
\text { League }\end{array}$ & 2 & $\begin{array}{c}\text { Xilin Gol } \\
\text { League }\end{array}$ & 2 & Tongliao & 2 & $\begin{array}{c}\text { Xilin Gol } \\
\text { League }\end{array}$ & 2 \\
\hline 10 & Tongliao & 2 & $\begin{array}{c}\text { hinggan } \\
\text { league }\end{array}$ & 2 & $\begin{array}{c}\text { hinggan } \\
\text { league }\end{array}$ & 2 & $\begin{array}{c}\text { Xilin Gol } \\
\text { League }\end{array}$ & 2 & $\begin{array}{c}\text { hinggan } \\
\text { league }\end{array}$ & 2 \\
\hline 11 & Hulunbuir & 1 & Hulunbuir & 1 & Hulunbuir & 1 & $\begin{array}{l}\text { hinggan } \\
\text { league }\end{array}$ & 2 & Hulunbuir & 1 \\
\hline 12 & alxa league & 1 & $\begin{array}{c}\text { alxa } \\
\text { league }\end{array}$ & 1 & $\begin{array}{c}\text { alxa } \\
\text { league }\end{array}$ & 1 & $\begin{array}{c}\text { alxa } \\
\text { league }\end{array}$ & 1 & $\begin{array}{c}\text { alxa } \\
\text { league }\end{array}$ & 1 \\
\hline
\end{tabular}

Point-in degree indicates the influence degree of other cities. It can be seen from Table 3 that the penetration degree of Baotou in 2008-2016 has always been in the first place, followed closely by Wulanchabu, Hohhot and Erdos, there is a large difference in point penetration, indicating that it has good economic relations with other cities and can better obtain the required resources. The Point penetration of Wulanchabu City is obviously greater than the point-out degree, indicating that it is more affected by other cities than its own influence on surrounding cities. This is because he is located in the geographical center of Inner Mongolia, located in a traffic fortress, inherited the economic exchanges between eastern and Western Mongolia ${ }^{[2]}$. The other cities are relatively small, and the economic radiation intensity of other cities is relatively weak. Most of the cities have more point-out than point-in, indicating that the impact on other cities is greater than accepting the impact of other cities. 
Table 4 Analysis on the central potential of Inner Mongolia's city economic ties

\begin{tabular}{c|c|c|c|c|c}
\hline Year & 2008 & 2010 & 2012 & 2014 & 2016 \\
\hline the central potential of Point-out degree & $17.03 \%$ & $17.48 \%$ & $17.59 \%$ & $16.23 \%$ & $14.86 \%$ \\
\hline the central potential of Point-in degree & $8.80 \%$ & $10.85 \%$ & $10.88 \%$ & $10.31 \%$ & $10.85 \%$ \\
\hline
\end{tabular}

The central potential is to quantitatively explore the extent to which the entire network shows a trend toward a certain point. The concentration trend is measured by the central potential index. The closer the index is to 1 , the more obvious the trend of network concentration and the higher the central potential ${ }^{[1]}$.From table 4,we can see that the degree of economic links between the Union cities from 2008 to 2016 has a centralized trend, and the point-out center potential has always been greater than the point-in center potential, indicating that the urban economic links network in Inner Mongolia is not balanced.

The point -out center potential is slowly decreasing, which indicates that the economic linkage network of Inner Mongolia cities is mainly concentrated in the core cities of Baotou, Wulanchabu, Erdos and Hohhot. The implementation of the "Hubao E" economic circle and other policies has reduced their cooperation, exchange, personnel exchanges and transaction cost, the scope of inter-city economic activities is gradually narrowing.

The point-in center potential is gradually increasing, which indicates that the economic radiation intensity of the core cities is gradually increasing, and and there are more exchanges of technology, trade and information with marginal cities, or the upgrading of urban transportation, information, logistics and other infrastructures, thus improving its ability to absorb and grow, and strengthen economic ties with core cities.

\subsection{Cohesive Subgroup analysis}

The cohesive Subgroup is based on the relationship model expressed in the group, and the members in the group have relatively strong, direct, close, frequent or positive relationships ${ }^{[1]}$.Through the Ucinet-Network-Concor operation steps, the non-overlapping cluster analysis of the cohesive subgroups of the economic linkage network of Inner Mongolia cities is carried out. The network cohesion subgroups between cities are not the classification of small groups within the ordinary urban groups ${ }^{[3]}$,but the analysis of which economic relations among these cities are strong, closely linked and actively cooperated. Determining cohesive subgroups and their affinities and distances, if there are more subgroups in the network, it will hinder the direct and extensive communication between the whole network members ${ }^{[4]}$.

Table 5 Analysis on cohesive subgroups in Inner Mongolia urban economic network

\begin{tabular}{c|c|c|c|c}
\hline Year & \multicolumn{4}{|c}{ Cohesive Subgroups } \\
\hline 2008/2010/2012 & 1 & Hohhot, ulanqab, Baotou, Ordos & 2 & Bayan Nur, Wuhai, alxa league \\
\cline { 2 - 5 }$/ 2014 / 2016$ & 3 & Chifeng, Hulunbuir, hinggan league & 4 & Tongliao, Xilin Gol League \\
\hline
\end{tabular}

From Table 5,it can be concluded that the members of cohesive Subgroups of Inner Mongolia urban economic links have not changed from 2008 to 2016.It can be divided into the following categories: First, the important economic impact of Hohhot ,Wulanchabu, Baotou and Erdos as subgroup; second, the cohesive subgroup formed by interaction between Bayannaoer, Wuhai and Alxa League; third, the economic relationship between Hulunbeier and Xing'an League as a subgroup and Chifeng; fourth, cohesive subgroup formed by Tongliao and Xilinguole Menthe members of cohesive subgroup 1 are the cities in central Inner Mongolia and the members of cohesive subgroup 2 are the cities in Western Inner Mongolia. The two subgroups are geographically related, while the members of cohesive subgroup 3 and cohesive subgroup 4 are the members of Eastern Inner Mongolia and are non-geographically related, which indicates that the 
members of these groups have closer economic ties, more frequent cooperation and transcend geographically related $^{[5]}$.

\section{Conclusion}

Generally speaking, Inner Mongolia's urban economic ties have been gradually strengthened. Because of the low starting point of economic development, there is much room for improvement. First of all, from the perspective of centrality analysis, the economic exchanges mainly focus on the "Hou Bao E" economic circle, which has strong radiation capacity and promotes the development of Inner Mongolia, however, the cities in Eastern Inner Mongolia are less affected by radiation. The centrality analysis of the Eastern Inner Mongolia found that it was not consistent with the change in GDP, indicating that compared with other alliances, Eastern Inner Mongolia and the three northeastern provinces have closer ties and mutually beneficial cooperation, thus promoting economic development. The economic links between cities are characterized by regional characteristics, and the development level gap between regions is widened, which is in line with the policies implemented by the state. Second, the economic links of the cohesive Subgroups with Hubao-E as the economic circle have shown a breakthrough growth, which can be compared with the cities in the coastal developed areas. The economic links among the other cohesive Subgroups differ greatly from those of Hubao-E, but the economic links between cohesive Subgroups and within cohesive Subgroup are strengthened, indicating that the barriers and contradictions between cohesive subgroups are weakening. Finally, the core-edge structure analysis results are consistent with the analysis results of the central degree. The members of the core area changed greatly under the influence of the Eleventh Five-Year Plan and the Twelfth Five-Year Plan. Finally, the members of the core area concentrated in the central Mongolia region, especially in the Hubao'e economic circle. The network connection density of the core area is much higher than that of the border area, and the economic linkage between cities is stepped ${ }^{[6]}$.

\section{References}

[1] Liu Jun.Overall Network Analysis: Guidelines for UCINET Software Use [M].Shanghai: Gezhi Publishing House,Shanghai People's Publishing House,2014.1-343.

[2] Liu Hehe,Yang Qingshan,Yang Bin,Feng Jing.Urban Development Research in Inner Mongolia from the Perspective of Urban Flow [J].Resource Development and Market,2014,10:1239-1242.

[3] Jin Haipan,Zheng Lin,Zhang Jingwei.An analysis of the social network of inter-city economic links in the Poyang Lake Eco-economic Zone[J].Journal of Jiangxi Normal University (Natural Science Edition),2014,05:546-550.

[4] Yuan Dan,Lei Hongzhen.Social Network Analysis of Economic Linkage and Coordinated Development of Silk Road Economic Belt [J].Journal of Yunnan University of Finance and Economics,2014,04:61-67.

[5] Yu Cauliflower,Cui Weijun.Analysis of the Network Characteristics of Urban Economic Links in Anhui Province [J].East China Economic Management,2012,09:34-39.

[6] Wang Ming.A study on the structure of economic connection network of Jiangsu urban agglomeration based on social network[J].Business Age,2012,27:138-139. 